\title{
VERB CHOICE IN MEDICAL RESEARCH ARTICLES (ESP)
}

\author{
Ilina Doykova*
}

\begin{abstract}
The corpus-based analysis of high frequency verbs used in research articles aims at establishing the lexical core, native and non-native researchers need for publishing in medicine. The verbs, extracted from two self-compiled corpora are structured as per the established format of the research article genre. The findings showed that in the Introduction, Methods, Results and Discussion sections there is great variation in the use of verbs, related to data observation, presentation, and description. Areas of difference in evaluative language and the preferred lexical structures in reporting scientific results are indicated. The predicative adjective construction is identified as a frequent strong verb substitute in the non-native scientific writing. Specific verb lists form a valuable source for the creation of teaching materials for university and PhD students.
\end{abstract}

Key words: English for specific purposes, medical research articles, verb variety

\section{Introduction}

The present paper is a corpus-based study of verbs introducing citations, presenting results, argumentation and discussion of findings or indicating stance in medical research articles (MRA). The aim is to compare the core scientific verbs used by international and Bulgarian researchers, publishing in English in terms of their specific use in English for specific purposes (ESP).

The observations of Swales and Feak (2004) and Nesselhauf (2005) on the problem areas in academic writing, experienced by graduate students have provoked multiple corpus-based and corpus-driven studies in various disciplines recently. The importance of word frequency in academic vocabulary is stated by Coxhead (2000) and further studied by Granger and Paquot (2009) who compare the use of lexical verbs by native writers and advanced learners of English for Academic Purposes (EAP) to show verb specificity in different fields (business, linguistics, and medicine). The MRA genre analysis resulted in the establishment of a Medical Academic Word List comprising 623 word families and frequently used words in 32 specific subject areas (Wang, Liang, Ge 2008) and contrastive studies of reporting verbs in various disciplines such as the use of reporting verbs in 25 MRA introduction sections (Jirapanakorn 2012).

* PhD at Medical University of Varna, Varna, Bulgaria, e-mail: ilina.doykova@abv.bg. 
In view of Hyland's (2002) and Hyland and Tse's (2007) approach to teaching academic language in its specificity, we believe that the Bulgarian community of researchers and doctoral students would benefit from the present analysis of MRA for an improved lexical choice and precision in their English writing. This study is motivated by the observations on the repetitive use of certain verbs, the overuse of passive voice, and the multiple revisions in the scientific writing courses at the Medical University of Varna.

\section{Research method}

All verb forms were statistically determined in 250 medical research articles with WordSmith Tools, Version 6 (Scott 2012) and the lexical items that occurred frequently in the separate sections of the medical RA were identified. The Bulgarian collection of MRA, published in English (BULRA corpus) was investigated for types of verbs, their active or passive use in the sentence and specific meaning. The BULRA corpus comprises 50 original papers and is gradually expanded to represent a broad specter of medical disciplines within the research article genre from peer-reviewed medical journals such as Acta Medica Bulgarica, Folia Medica, Journal of Biomedical and Clinical Research, Scripta Scientifica Medica and Trakia Journal of Sciences. Each paper is written by a different group of researchers and recently published (2015-2017). The total number of tokens (running words) in the BULRA collection is 167957 (15 112 word types) and a lexical density of 27.39 words in 5138 sentences.

The second collection of research articles of international researchers (INTRA corpus) contains 200 open access research papers, published in BioMed Central journal. This influential journal was selected and served as a reference corpus for its high impact factor (8.005). The size of the INTRA corpus is 955,104 words (25 097 word types) with a lexical density of 35.51 words in 12363 sentences. The articles cover various fields in medicine such as surgery, clinical pathology, dermatology, nephrology, cardiovascular disorders, infectious diseases, nutrition, etc. A keyword list of all used verbs was compiled and compared to the BULRA keyword list of verbs.

\section{Research question: Identification of key verbs in MRA}

To identify the verbs, characteristic of the medical research articles and eliminate past participle (A) and attributive adjective use (B), the BULRA corpus was grammatically annotated with the CLAWS C7 tagger (Fig. 1), developed at Lancaster University for parts of speech tags such as modal verb (VMO), infinitive forms (VVI), present and past participle (VVG, VVN) tags: 
A. The rate of complications observed in PNS varies with different authors, although the method is minimally invasive.

B. Like other authors, we associated the observed hypovitaminosis with the reduced activity of the alpha-1-hy-droxylase, mild expression of vitamin D receptors and an increased loss of vitamin D transport proteins [12, 13, 14].

The_AT0 exact_AJ0 diagnosis_NN1 of_PRF chronic_AJ0 myofascial_AJ0 and_CJC temporomandibular_AJ0 pain_NN1 conditions_NN2 is_VBZ often_AV0 quite_AV0 a_AT0 challenge_NN1 for_PRP clinicians_NN2 that CJT have_VHB to_TO0 unravel_VVI the_AT0 puzzle_NN1._SENT_PUN The_AT0 present_AJ0 investigation_NN1 provided_CJS findings_NN2 that_CJT can_VM0 be_VBI useful_AJ0 to_TO0 create_VVI a_AT0 worldwide_AJ0 database_NN1

Fig. 1 Verbs in BULRA corpus

\section{Data analysis}

The verbs in the corpus were sorted in a quantitative wordlist according to their frequency of occurrence and subsequently lemmatized. All verb forms from the BULRA wordlist were compared to the INTRA wordlist to obtain the keywords (high frequency verbs in both corpora) and the key verbs were observed and analyzed in concordance lines. The comparison revealed that certain key verbs occur more often in BULRA corpus and other verbs are not typically used as the negative key verbs in Fig.2:

\begin{tabular}{|c|c|c|c|c|c|c|c|c|c|}
\hline \multicolumn{10}{|c|}{ File fest View Compule Settings Windows Help } \\
\hline & N & & Key word & Freq. & $*$ & Texts & $\begin{array}{l}\text { RC. } \\
\text { Freq. }\end{array}$ & RC. $*$ & Kevness \\
\hline & 1 & & SHOWED & 112 & 0,08 & 17 & 0 & & 455,06 \\
\hline & 2 & & PRESENT & 97 & 0,07 & 25 & 0 & & 394,11 \\
\hline & 3 & & COMPARED & 90 & 0,06 & 23 & 0 & & 365,66 \\
\hline & 4 & & LEADS & 62 & 0,04 & 14 & 69 & & 90,06 \\
\hline & 5 & & DEFINED & 18 & 0,01 & 12 & 0 & & 73,12 \\
\hline & 6 & & EVALUATED & 15 & 0,01 & 9 & 0 & & 60,94 \\
\hline & 7 & & PROVIDE & 14 & & 7 & 0 & & 56,87 \\
\hline & 8 & & TREATED & 99 & 0,07 & 14 & 337 & 0,04 & 29,83 \\
\hline & 9 & & REDUCES & 23 & 0,02 & 7 & 31 & & 28,48 \\
\hline & 10 & & COULETED & 10 & & 6 & 265 & 0,03 & $-29,24$ \\
\hline & 11 & & CONSIDERED & 36 & 0,02 & 20 & 545 & 0,06 & $-29,56$ \\
\hline I & 12 & & ESTIMATE & 8 & & 3 & 246 & 0,03 & $-30,62$ \\
\hline
\end{tabular}

Fig. 2 Keyword list in BULRA corpus

The choice of reporting verbs enables the writers to position their work in relation to that of other members of the research community. Following Thompson and 
Ye's classification (1991) and according to their potential and function in the MRA, these may be categorized as textual (discourse verbs), mental (cognition verbs) and research (experimental) verbs. Other classifications such as Thomas and Hawes' (1994) and Hyland's (2002) use similar group names which are added here for reference (in brackets). The overuse of verbs, denoting static relations and passive voice forms together with the most frequent neutral verbs of reporting is illustrated in BULRA corpus (Table 1).

\begin{tabular}{|l|l|}
\hline \multicolumn{1}{|c|}{ Lemma } & Occurrences \\
\hline Be [be, been, being, is, are, was, were] & 3444 \\
\hline Have [have, has, had] & 563 \\
\hline Show [show, shows, shown, showed] & 236 \\
\hline Find [find, finds, found] & 189 \\
\hline Use [use, uses, used] & 126 \\
\hline Report [report, reports, reported] & 114 \\
\hline Present [present, presents, presented] & 106 \\
\hline Occur [occurs, occurred] & 83 \\
\hline Observe [observe, observed] & 69 \\
\hline Demonstrate [demonstrate, demonstrated] & 56 \\
\hline
\end{tabular}

Table 1. Overused verbs in BULRA corpus

The extracted verbs from the INTRA corpus show a considerable degree of variation and use in comparison to BULRA corpus. The notion of 'optimal viewing arrangement", introduced by Langacker (1987) predetermines the use of impersonal sentences, sentences with suppressed agentivity (in passive voice), and the high percentage of predicative adjective constructions in research articles (be required, be recommended, be needed, be used, be prescribed, be considered, be consistent with). Resultative constructions are supplied by many sources ( $3 r d$ plural impersonal, reflexive verbs, and perfective aspect) to achieve such prominent features of scientific writing as objectivity and impersonal style (Hyland 2002).

The cluster analysis of frequent verbs and their patterns in BULRA shows passive voice preference and lack of variation in sentence structure (Fig.3a, b). 


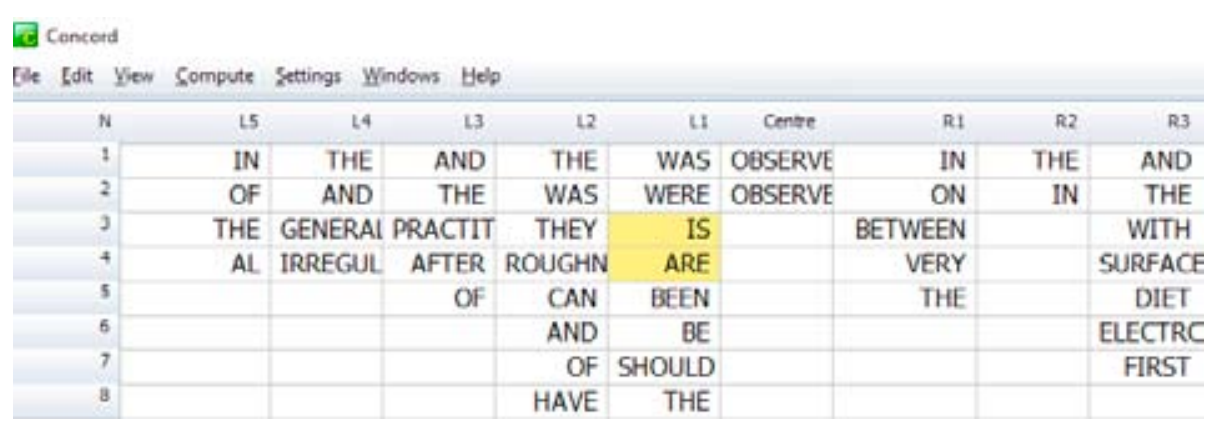

Fig. 3a Patterns of observe in BULRA corpus

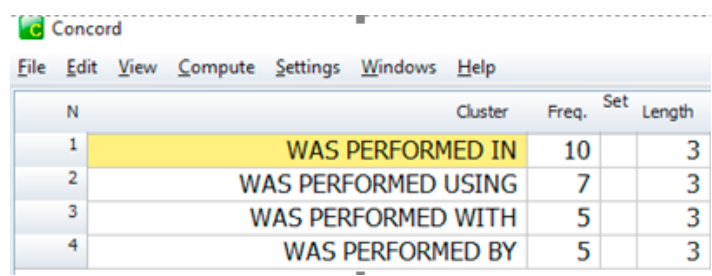

Fig. 3b Patterns of perform

Further on, frequent negative predicative adjective constructions with stative reading (not important, not essential, not able, not certain) may be replaced by equivalent verbs or negatively prefixed constructions (fail, lack, be absent, be arguable, be inferior, be insufficient, be incomplete) for an improved readability and stronger focus on the presented results. Sentences in need of revision are the following samples:

1. The low response rate and mixed sampling inhibits generalization of the findings, but this was not our objective and, given the sufficient breadth of the data, it should not be concerning.

2. Although the exact mechanism involved in burn-induced mucosal damage is not clear yet, increasing evidence indicates decreased gastric mucosal blood flow, local and systemic liberation of cytokines and reactive oxidant intermediaries and changes in production of nitric oxide (NO) and prostaglandins (PGs) as a factor of mucosal damage (2-4).

3. Besides, the available laboratories are not able to meet the diagnostic demand of all the patients with CHF.12,26 Type 4 screening devices (one or two channels) are a meaningful solution to detect patients with SDB. 
Common verbs be, test, show, have, make, give, take have specific lexical verb substitutes which add elegance and formality to scientific writing (conclude, find, indicate, demonstrate, reveal, emphasize, support, allow for, exist, occur, appear, arise, emerge, observe, assess, achieve, measure, determine, confirm, etc.) and the collocations could be established with the help of a reference corpus search. For example, the verb make is not the right choice for the noun experiment (*make an experiment) but rather a literal translation of the Bulgarian phrase (правя експеримент) and when collocations are verified in the British National Corpus it becomes evident that only one lexical element in the collocation is identical. Thus, verbs such as carry out/perform/conduct prove to be the noun company (Fig. 4).

\begin{tabular}{|c|c|c|c|}
\hline CARRITD & 41 & 12300 & a.31 \\
\hline CONDUCteD & 25 & 2937 & 1.18 \\
\hline Dinsolute & 20 & 3809 & 0.72 \\
\hline OESERNATION & 27 & 277 & 0.97 \\
\hline subects & 27 & 7614 & o.s5 \\
\hline SUCCESSFUL & 25 & 10564 & 0.24 \\
\hline Explandent & 24 & $300 t$ & o.rin \\
\hline
\end{tabular}

Fig. $4 \mathrm{BNC}$ search for collocations of $n$. experiment

In order to avoid such 'omnipresent' verbs and to strive for brevity and conciseness in scientific writing, verb-noun collocations (make an assessment, make a presentation, make a conclusion) may be replaced by specific verbs (assess, present, conclude) for an improved readability. Cognition verbs found in BULRA corpus (appear, suggest, seem) should also be used with care and limit:

4. Overall, although there was some evidence to suggest higher risk of IHD morbidity, it was limited.

5. In univariate analysis only two of the factors appeared to be significantly associated with the disease free survival (Table 2): $\mathrm{T}$ and $\mathrm{N}$ staging.

6. We think that a mix of hormones, their interplay with cytokines and the insulin signaling pathway seem to be responsible for the metabolic changes occurring during pregnancy.

Over the years academic writing style has been studied by many linguists such as Bell (1995), Swales and Feak (2004), Zeiger (2000), Gustavii (2017) and many others, who recommend the active voice as the more precise, shorter, and clearer alternative to the passive for all parts of the research article but Materials and Methods where it is used to emphasize findings. Thus, the revised versions of the passive sentences from BULRA corpus highlight the main idea (Table 2): 
BULRA samples

Revision

\begin{tabular}{|l|l|}
\hline $\begin{array}{c}\text { 7. In order to provide more significant } \\
\text { results after Er: YAG laser treatment, } \\
\text { further investigation is needed in the } \\
\text { future. }\end{array}$ & $\begin{array}{l}\text { Future investigations will } \\
\text { provide significant results! }\end{array}$ \\
\hline $\begin{array}{c}\text { 8. Antibiotics and steroids are often } \text { used } \\
\text { to treat the lesions. }\end{array}$ & $\begin{array}{l}\text { Lesions are often treated with } \\
\text { antibiotics and steroids. }\end{array}$ \\
\hline $\begin{array}{c}\text { 9. The method was used as a main and } \\
\text { only method with } 98 \% \text { success in } \\
\text { conservative dentistry. }\end{array}$ & $\begin{array}{l}\text { This method was } 98 \% \\
\text { successful in conservative } \\
\text { dentistry. }\end{array}$ \\
\hline $\begin{array}{l}\text { 10. Epidural abscess formation with a } \\
\text { craniocaudal length of } 3.5 \mathrm{~cm} \text { at this } \\
\text { level was observed. }\end{array}$ & $\begin{array}{l}\text { We observed an epidural } \\
\text { abscess formation ... }\end{array}$ \\
\hline
\end{tabular}

Table 2. Improved readability after passive-to-active transformation

Thus, the external view point on behalf of the researcher is still preferred in the Bulgarian scientific writing and remains the dominant strategy in achieving objectivity. Sentences in the active voice with inanimate agents are the second syntactic option, featured in scientific writing. Contrary to academic writing in Bulgarian, the use of reporting verbs in combination with non-human subjects breaks no grammar conventions:

11. However, our approach accurately predicts whether an emerging pathogen remains below the critical epidemic threshold $(\mathrm{R}<1)$.

12. Our results indicate that serum iron reflects the iron deficiency and inflammatory activity: the amount of serum iron was significantly higher in healthy controls compared to RA ( $\mathrm{P}=0.014)$ (Table 1), which confirmed the hypoferremia condition in RA patients.

13. These data clearly demonstrate that MitoQ not only suppresses release of the active forms of IL-1 beta and IL-18, but also their transcriptional upregulation.

14. Recent research has suggested that cognitive disorders are a persistent trait of mental illnesses such as schizophrenia.

\section{Results and Discussion}

The present analysis showed that past participles, functioning either in predicative adjective patterns or in passive sentences, dominate the MRA texts. Past participles may represent resultative states or actions with a different degree of verbality or stability. In predicative adjective patterns, the verb be functions as a main verb with a stative reading and the past participle expresses a property/ 
state in predication and in passive voice it is used to denote a resultative action (Doykova, Sezova-Nankova 2015). Thus, when a resultative state, a fact, or a completed past action is described, researchers resort to verbal passive and stative resultative constructions (Appendix 1). Predicative adjectives referring to states as being more time-stable than verbs (Haspelmath1994) are also frequent.

The dominant verbs in the INTRA corpus vary slightly in their rank (as per frequency of use) when compared to the BULRA corpus but experimental verbs occupy top positions in both corpora (Table 3). Highly ranked certainty verbs that are found exclusively in BULRA are demonstrate, determine, detect, test, affect, establish, lead, diagnose. Tentative verbs such as recommend, hypothesize, speculate are rarely used.

\begin{tabular}{|c|c|c|c|c|c|}
\hline \multirow[t]{2}{*}{ Rank } & \multicolumn{2}{|c|}{ BULRA } & \multirow[t]{2}{*}{ Rank } & \multicolumn{2}{|c|}{ INTRA } \\
\hline & Verb & Frequency & & Verb & Frequency \\
\hline 1 & use & 120 & 1 & study & 895 \\
\hline 2 & increase & 109 & 2 & use & 763 \\
\hline 3 & perform & 68 & 3 & report & 704 \\
\hline 4 & report & 78 & 4 & show & 686 \\
\hline 5 & lead & 63 & 5 & associate & 560 \\
\hline 6 & cause & 60 & 6 & find & 541 \\
\hline 7 & determine & 58 & 7 & increase & 522 \\
\hline 8 & demonstrate & 56 & 8 & observe & 498 \\
\hline 9 & show & 53 & 9 & include & 476 \\
\hline 10 & observe & 51 & 10 & identify & 434 \\
\hline 11 & establish & 50 & 11 & perform & 409 \\
\hline 12 & include & 47 & 12 & consider & 374 \\
\hline 13 & find & 46 & 13 & estimate & 317 \\
\hline 14 & consider & 41 & 14 & assess & 275 \\
\hline 15 & suggest & 41 & 15 & conduct & 264 \\
\hline 16 & present & 39 & 16 & describe & 235 \\
\hline 17 & treat & 38 & 17 & obtain & 231 \\
\hline 18 & study & 37 & 18 & provide & 212 \\
\hline 19 & occur & 32 & 19 & see & 204 \\
\hline 20 & detect & 28 & 20 & calculate & 201 \\
\hline 21 & test & 24 & 21 & measure & 198 \\
\hline 22 & analyze & 24 & 22 & present & 186 \\
\hline 23 & compare & 22 & 23 & treat & 153 \\
\hline 24 & present & 21 & 24 & analyze & 146 \\
\hline 25 & apply & 20 & 25 & indicate & 128 \\
\hline
\end{tabular}

Table 3. Top 25 verbs in BULRA and INTRA corpora 
The key verbs and predicative adjective constructions, extracted from INTRA corpus demonstrate greater variety and specificity in the separate IMRD sections of the medical research article (Table 4):

\begin{tabular}{|c|c|}
\hline $\begin{array}{l}\text { Presenting the } \\
\text { research topic }\end{array}$ & $\begin{array}{l}\text { investigate, examine, explore, determine, compare, analyze, } \\
\text { assess, consider, evaluate, estimate, describe, develop, } \\
\text { discuss, see, argue, indicate, hypothesize, concentrate on, } \\
\text { focus on, propose, note, report, study, show, attempt to, } \\
\text { examine, conduct, provide insight, would be useful, carry } \\
\text { out, should be investigated, may be developed, better } \\
\text { understand, deal with, aim at, motivate, report, address, } \\
\text { validate, review }\end{array}$ \\
\hline $\begin{array}{l}\text { (Materials } \\
\& \\
\text { Methods) }\end{array}$ & $\begin{array}{l}\text { use, perform, analyze, conduct, test, perform, compute, } \\
\text { recruit, select, enroll, choose, include, exclude, allocate, } \\
\text { assign, group, divide, randomize, categorize, stratify, } \\
\text { obtain, maintain, acquire, carry out, collect, gather, retrieve, } \\
\text { assess, evaluate, consider, ascertain, measure, determine, } \\
\text { define, detect, explore, calculate, compute, record, examine, } \\
\text { classify, estimate, determine, use, apply, employ, present, } \\
\text { summarize, express, associate, attempt, illustrate, identify, } \\
\text { reveal, conduct, detect, investigate, establish, perform }\end{array}$ \\
\hline Reporting & $\begin{array}{l}\text { assess, evaluate, examine, study, explore, compare to/ } \\
\text { with, contrast, match, characterize, probe, relate, correlate, } \\
\text { associate, demonstrate, highlight, test, inform, confirm, } \\
\text { ensure, establish, verify, obtain, differ, reduce, be related } \\
\text { to, be similar, be different, show, indicate, suggest, reveal, } \\
\text { exhibit, illustrate, exemplify, affirm, assert, testify, interpret, } \\
\text { define, report, reveal, find, observe, view, review, perceive, } \\
\text { regard, approach, study, have, present, perform, summarize, } \\
\text { involve, search, survey, inspect, inquire, explore, investigate, } \\
\text { identify, check, detect, determine, assess, analyze, calculate, } \\
\text { ascertain, provide evidence, employ, utilize, implement }\end{array}$ \\
\hline (Discussion) & $\begin{array}{l}\text { associate to/with, correlate with, interact with, find, observe, } \\
\text { use, explain, demonstrate, indicate, reveal, yield, explore, } \\
\text { reason, clarify, confirm, occur, consider, need, examine, } \\
\text { investigate, support, present, evaluate, reflect, provide, be } \\
\text { consistent with, be attributed to, be applied to, suggest, } \\
\text { propose, examine, establish, assume, assess, highlight, } \\
\text { include, indicate, agree with, be limited to, be required, be } \\
\text { needed, be essential, be bias free, speculate, report, suggest, } \\
\text { note, predict, recommend, describe, indicate, emphasize }\end{array}$ \\
\hline
\end{tabular}




\begin{tabular}{|l|l|}
\hline Concluding & $\begin{array}{l}\text { conclude, present, propose, recommend, demonstrate, } \\
\text { determine, assess, observe, show, summarize, suggest, serve, } \\
\text { enhance, add to, support, find, estimate, identify, influence, } \\
\text { contribute, be required, be recommended, be needed, be } \\
\text { necessary, be prescribed, be considered, be helpful, be } \\
\text { useful, need to, consider, focus (on), believe, think, refer }\end{array}$ \\
\hline
\end{tabular}

\section{Table 4. Verbs and predicative adjective constructions, INTRA corpus}

Bulgarian authors adhere to neutral verbs and few verbs of cognition (consider) occur only in the conclusions section of the MRA. Contrary to the Bulgarian corpus, evaluative, mental and experimental verbs are preferred in INTRA corpus and suggestive of the type of research activities (assess, estimate, consider, indicate, identify). Strong evaluative verbs such as argue, support, confirm, claim, believe, associate, provide, conduct, treat, assess, estimate, indicate are also frequent in INTRA.

Worth mentioning is the similar use of research verbs such as show, report, observe, find, use, perform, analyze, study, include by both groups of researchers which could be attributed to their universal function in scientific discourse. Greater difference is found in the tense choice and verb meaning (suggest vs. propose) which points to certain grammar and lexical issues for further investigation.

\section{Conclusions}

In the standard four-section structure of the medical research article(Introduction, Methods, Results, and Discussion) a variety of verbs are employed to present the findings and produce a convincing manuscript. The purpose of the corpusbased study was to extract, describe and compare the characteristic use of lexical verbs, non-native speakers overuse or misuse in scientific papers. The set of 120 discipline-specific verbs from the specialized corpus will assist novice writers in their vocabulary development and writing practice. The specificity of the RA genre necessitates conventional choice of grammar and lexis which should be incorporated in the language teaching for specific purposes. The process of expanding the two corpora is on-going with the intention to investigate the variety of structures and the specifics of the MRA genre for effective instruction and course-book design.

\section{References:}

Bell 1995: Bell L. Effective Writing: A Guide for Health Professionals. Copp Clark, University of Michigan.

Coxhead 2000: Coxhead A. A New Academic Word List. - TESOL Quarterly. 34(2). 213238. 
Doykova, Seizova-Nankova 2015: Doykova, I., T. Sezova-Nankova. Identification of the Category of Adjective in English. A Corpus-based Approach. - In: Cheshmedzhieva D. (ed.). The Global and the Local: Modern Trends in English Studies and Translation. Shumen: Konstantin Preslavsky University Press. 38-50.

Granger, Paquot 2009: Granger S., M. Paquot. February. In search of a General Academic Vocabulary: A Corpus-Driven Study. - In: Charles M., Pecorari D., S. Hunston (eds.). Academic Writing. At the Interface of Corpus and Discourse. Continuum. 193-214.

Gustavii 2017: Gustavii B. How to Write and Illustrate a Scientific Paper. Cambridge University Press.

Haspelmath 1994: Haspelmath M. Passive Participles across Languages. - In: Fox B., P. J. Hopper (eds.). Voice: Form and Function. Amsterdam: Benjamins.151-177.

Hyland 2002: Hyland K. Specificity Revisited: How Far Should We Go Now? - English for Specific Purposes. 21(4), 385-395.

Hyland, Tse 2007: Hyland K., P. Tse. Is There an "Academic Vocabulary"? - TESOL Quarterly. 41(2), 235-253.

Jirapanakorn 2012 Jirapanakorn N. How Doctors Report: A Corpus-Based Contrastive Analysis of Reporting Verbs in Research Article Introductions Published in International and Thai Medical Journals. - The Bangkok Medical Journal. 4, 39-46.

Langacker 1987: Langacker R. Foundations of Cognitive Grammar. Vol.1 Theoretical Prerequisites, Stanford, CA: Stanford University Press.

Nesselhauf 2005: Nesselhauf N. Collocations in a Learner Corpus. Amsterdam: Benjamins.

Scott 2012: Scott M. WordSmith Tools 6. Oxford: Oxford University Press.

Swales, Feak 2004: Swales J., C. Feak. Academic Writing for Graduate Students. Essential Tasks and Skills. The University of Michigan Press.

Thomas, Hawes 1994: Thomas S., T. Hawes. Reporting Verbs in Medical Journal Articles. - English for Specific Purposes. 13(2).129-148.

Thompson, Ye 1991: Thompson G., Y. Ye. Evaluation in the Reporting Verbs Used in Academic Papers. - Applied Linguistics. 12(4), 365-382.

Wang, Liang, Ge 2008: Wang J, Liang S, G. Ge. Establishment of a Medical Academic Word List. - English for Specific Purposes. 27, 442-458.

Zeiger 2000: Zeiger M. Essentials of Writing Biomedical Research Papers. New York: McGraw-Hill.

\section{Internet sources}

Acta Medica Bulgarica. <https://www.degruyter.com/>

Folia Medica. $<$ https://foliamedica.bg/>

Journal of Biomedical and Clinical Research. $<$ http://jbcr.mu-pleven.bg/>

Scripta Scientifica Medica. <http://press.mu-varna.bg/ojs/index.php/ssm/issue/archive >

Trakia Journal of Sciences. $<$ http://tru.uni-sz.bg/tsj/>

BioMedcentral journal. $<$ https://www.biomedcentral.com $>$

CLAWS C7. <http://ucrel.lancs.ac.uk/cgi-bin/claws72.pl>

British National Corpus. <http://www.natcorp.ox.ac.uk/> 


\section{Appendix 1. Passive constructions and predicative adjective patterns in BULRA corpus}

\begin{tabular}{|l|l|l|}
\hline \multicolumn{2}{|c|}{$\left[\mathrm{V}_{\text {pass }}\right]$} & \multicolumn{1}{|c|}{$[$ be] +[Adj] } \\
\hline performed (69) & known (17) & be available (34) \\
increased (20) & conducted (16) & be similar (26) \\
included (52) & achieved (15) & be necessary (17) \\
established (47) & indicated (15) & be difficult (15) \\
determined (45) & obtained (14) & be responsible (13) \\
considered (39) & evaluated (13) & be useful (10) \\
treated (36) & expected (13) & be limited (8) \\
made (30) & affected (12) & be appropriate (7) \\
applied (29) & assessed (12) & be different (7) \\
identified (28) & carried out (11) & be crucial (5) \\
investigated (28) & given (9) & be consistent with (5) \\
analyzed (27) & examined (8) & be helpful (3) \\
expressed (27) & accepted (8) & be apparent (2) \\
described (25) & allowed (8) & be essential (2) \\
confirmed (25) & processed (8) & \\
detected (23) & approved (8) & \\
measured (23) & introduced (8) & \\
diagnosed (22) & needed (8) & \\
tested (22) & recommended (7) \\
seen (21) & prescribed (7) & \\
estimated (20) & be required (4) & \\
\end{tabular}

\section{Appendix 2. Specific verbs in medical research articles, INTRA corpus}

acquire, add, address, affirm, agree, aim, allocate, analyze, apply, argue, assert, ascertain, assess, assign, associate, assume, attempt (to), believe, calculate, carry out, categorize, characterize, check, choose, claim, clarify, classify, collect, compare, compute, contrast, concentrate (on), conclude, conduct, 
confirm, consider, contribute, correlate, deal (with), define, demonstrate, describe, detect, determine, develop, differ, discuss, divide, emphasize, employ, enhance, enroll, ensure, establish, estimate, evaluate, examine, exclude, exemplify, exhibit, explain, explore, express, find, focus (on), gather, highlight, hypothesize, identify, illustrate, include, indicate, influence, inquire, inspect, interact (with), interpret, investigate, involve, maintain, measure, motivate, need (to), note, observe, obtain, occur, perceive, perform, present, propose, provide, recommend, recruit, reduce, reflect, report, retrieve, reveal, record, review, search, see, select, serve, show, speculate, stratify, study, suggest, summarize, support, test, testify, understand, use, validate, verify, yield (120) 